\title{
A Low Power, Fully Differential Bulk Driven OTA in 180 nm CMOS Technology
}

\author{
Rekha S. and Laxminidhi T.
}

\begin{abstract}
A low voltage, low power bulk driven Operational Transconductance Amplifier (OTA) with feed-forward compensation is presented. The OTA is designed in $180 \mathrm{~nm}$ technology and achieves an open loop DC gain of $44.05 \mathrm{~dB}, 3 \mathrm{~dB}$ bandwidth of $408 \mathrm{kHz}$ and Unity Gain Bandwidth (UGB) of 9.07 MHz. OTA is stable with phase margin of $45^{\circ}$ and a gain margin of $66 \mathrm{~dB}$ for a pure capacitive load of $1 \mathrm{pF}$. OTA operates on $0.5 \mathrm{~V}$ supply consuming a power of $30 \mu \mathrm{W}$. As an application, a fifth order Chebyshev low pass filter is designed for a bandwidth of $480 \mathrm{kHz}$. Filter follows the ideal response up to an attenuation of $50 \mathrm{~dB}$.
\end{abstract}

Index Terms-Bulk driven, CMOS, feed-forward frequency compensation

\section{INTRODUCTION}

One of the important analog modules on a System On Chip (SOC) is the continuous time filter performing tasks like antialiasing, equalization etc. Filters used in biomedical applications like heart rate detectors and hearing aids etc., and front end of the sensor networks demand small size and low power consumption. Popular topologies of filters include active- $\mathrm{RC}$ and Transconductance $-\mathrm{C}$ filters. Among these, because of negative feedback, active-RC filters provide higher dynamic range for a given power. Operational Amplifier (Opamp) is the main building block of the active-RC filter. However, low output impedance requirement of Opamp makes it power hungry. For this reason, OTAs are widely used in place of Opamps but with some careful design [1], [2]. Various designs of OTA are described in the literature. This paper presents the design of a low power OTA for low power applications.

Scaling dimensions in CMOS technology requires proportional scaling in supply voltage as well. Though lower supply voltages result in lower power consumption, as the supply reduces there is a need to maintain relatively larger threshold voltage in order to reduce subthreshold currents. One of the circuit techniques to overcome this threshold voltage problem is to use bulk driven input MOSFETs which are operated in weak inversion mode. The first bulk driven MOS transistor concept was proposed in [3] in 1987. According to this concept, the signal is applied to the bulk nodes of the MOSFETs whereas biasing is done through the gates of the devices. Bulk modulates the current flow through

Manuscript received in April 13, 2012; revised May 24, 2012. This work was supported in part by the Department of Information Technology, MCIT, and GOI.

The authors are with National Institute of Technology Karnataka, Surathkal(e-mail: rsbhat_99@yahoo.com, laxminidhi_t@yahoo.com). the transistor. In [3], a bulk driven OTA is proposed. The research there on led to many bulk driven OTA designs, for example [4].

Commonly used Miller compensation scheme to stabilize the OTA in feedback, suffers from poor gain-bandwidth product. When such a OTA is used to realize a filter, the realizable filter bandwidth is limited by the OTA gain-bandwidth. Feed-forward compensation scheme is found to be effective in pushing the gain-bandwidth product of the OTA to a higher value [5]- [7].

\section{FEED-FORWARD OTA}

The block schematic of fully differential feed-forward compensated OTA is shown in Fig. 1 [7]. In the figure, $\mathrm{g}_{\mathrm{m} 1}$ and $g_{\mathrm{m} 2}$ are fully differential transconductors forming the forward path of the OTA and $\mathrm{g}_{\mathrm{m} 3}$, also a fully differential transconductor, forming the feed-forward path. A simplified single ended model of the OTA in Fig. 1 is shown in Fig. 2. The corresponding transfer function can be written as follows.

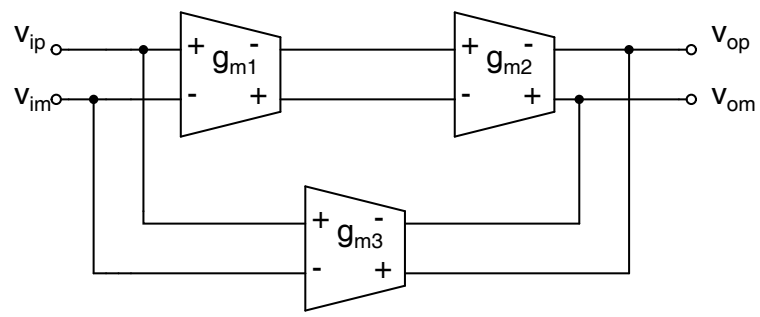

Fig. 1. Fully differential feed-forward compensated OTA

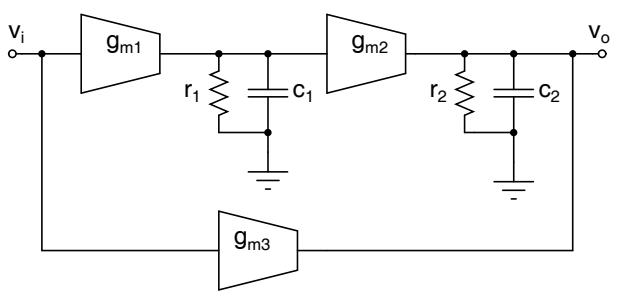

Fig. 2. Single ended Feed-forward compensated OTA

$$
\frac{V_{o}}{V_{i}}=\frac{g_{m 1} g_{m 2} r_{1} r_{2}\left[1+\frac{s}{\omega_{z}}\right]}{\left[1+\frac{s}{\omega_{p 1}}\right]\left[1+\frac{s}{\omega_{p 2}}\right]}
$$

where $\omega_{p 1}=\frac{1}{r_{1} c_{1}}, \omega_{p 2}=\frac{1}{r_{2} c_{2}}$ and $\omega_{z}=\frac{\omega_{p 1} g_{m 1} g_{m 2} r_{1}}{g_{m 3}}$. 
The feed-forward path thus introduces a left half s-plane zero at $\mathrm{s}=-\omega_{z}$ which improves the phase margin of the OTA without compromising the band width.

\section{Fully DifFERENTIAL BULK DRIVEN TRAN CONDUCTOR}

It is a common practice to use source coupled differential pair to realize the transconductor. But due to the limitations on overhead when operating with low supply voltages, it is common to use a pseudo differential architecture. A pseudo differential transconductor is shown in Fig. 3. In the figure, vip and vim are the differential inputs and vop and vom are the differential outputs. M1 and M2 are the input transistors operating in saturation. M3 and M4 form the NMOS loads and operate in weak inversion.

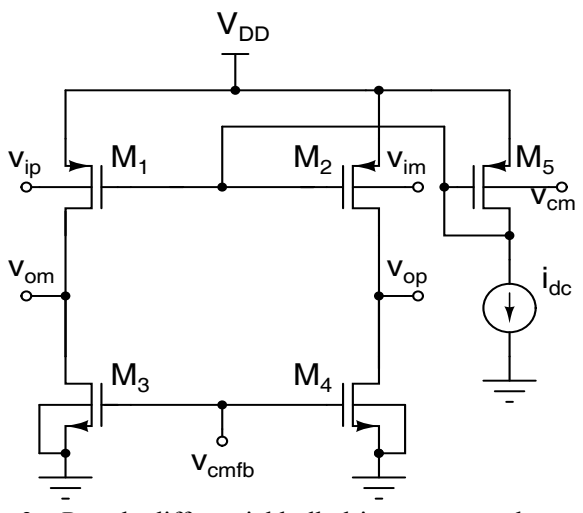

Fig. 3. Pseudo differential bulk driven transconductor

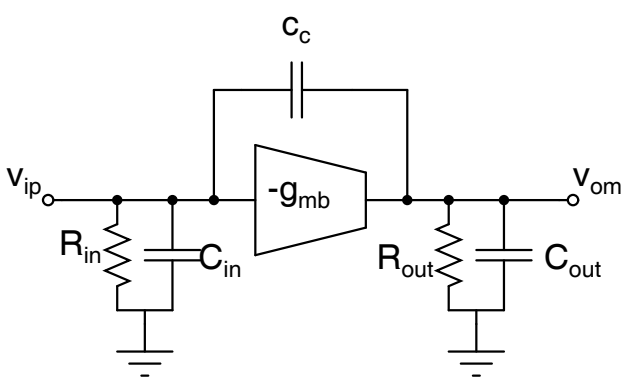

Fig. 4. Single ended small signal model of the transconductor

A single ended small signal equivalent circuit of the differential transconductor is shown in Fig. 4. In the figure, $\mathrm{g}_{\mathrm{mb}}$ is the transconductance of bulk driven transistor $\left(\mathrm{M}_{1} /\right.$ $\mathrm{M}_{2}$ ). $\mathrm{C}_{\text {in }}$ and $\mathrm{C}_{\text {out }}$ are the effective capacitances at input and output respectively. Similarly, $\mathrm{R}_{\mathrm{in}}$ and $\mathrm{R}_{\text {out }}$ are the effective input and output resistances respectively. $\mathrm{C}_{\mathrm{c}}$ is the effective coupling capacitance between the input and the output (bulk and the drain). This coupling capacitance can not be ignored as it is the drain junction capacitance and it introduces a right half plane zero. A simple scheme to compensate for this effect is shown in Fig. 5. It is to be noted that this will only compensate for the capacitance but will not cancel the capacitance altogether.

\section{BULK DRIVEN FEED-ForWARD OTA}

Bulk driven feed-forward OTA shown in Fig. 1 is realized using the differential transconductor shown in Fig. 5. Single ended small signal equivalent circuit of the differential feed-forward OTA is shown in Fig. 6 and the corresponding transfer function can be written as in (2).

$$
\frac{V_{o}}{V_{i}}=\frac{g_{m b}{ }^{2} r_{1} r_{2}\left[1-\frac{s c_{c}}{g_{m b}}\right]\left[1+\frac{\left(c_{1}+c_{c}\right) s}{g_{m b}}\right]}{A s^{2}+B s+1}
$$

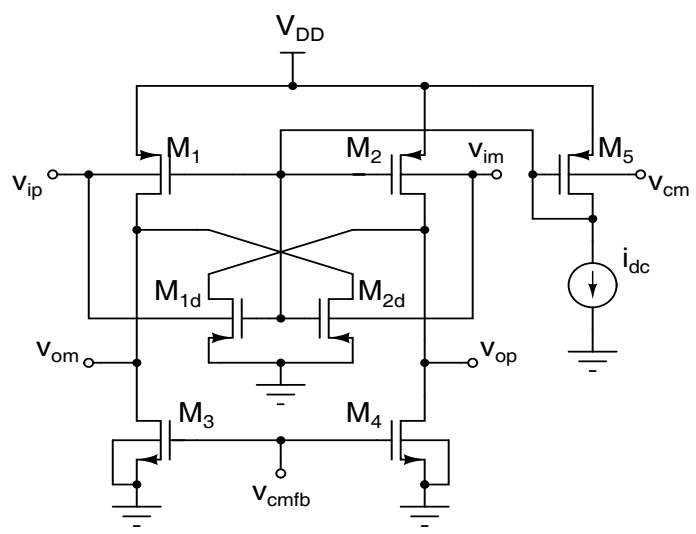

Fig. 5. Fully differential Bulk driven Transconductor

where

$$
\begin{aligned}
& A=r_{1} r_{2}\left(c_{1} c_{2}+2 c_{c} c_{1}+2 c_{c} c_{2}+3 c_{c}^{2}\right), \\
& B=r_{1} c_{1}+r_{2} c_{2}+g_{m b} r_{1} r_{2} c_{2}
\end{aligned}
$$

And $r 1, c_{1}$ and $r_{2}, c_{2}$ represent the effective impedance seen at the intermediate node of the forward path and output respectively with respect to small signal ground. In (2), it can be seen that there are two zeros, one on the left half of s-plane (at $\frac{-g_{m b}}{c_{1}+c_{c}}$ )and the other on the right half of s-plane (at $\left.\frac{g_{m b}}{c_{c}}\right)$. While the left half plane zero is introduced by the feed-forward transconductor to compensate the OTA, the right half plane zero is introduced due to the coupling capacitance, $c_{c}$. Note that the transistors $\mathrm{M}_{1 \mathrm{~d}}$ and $\mathrm{M}_{2 \mathrm{~d}}$ in Fig. 5 attempt to reduce $c_{c}$ to a minimum so that the effect of right half plane zero is minimized.

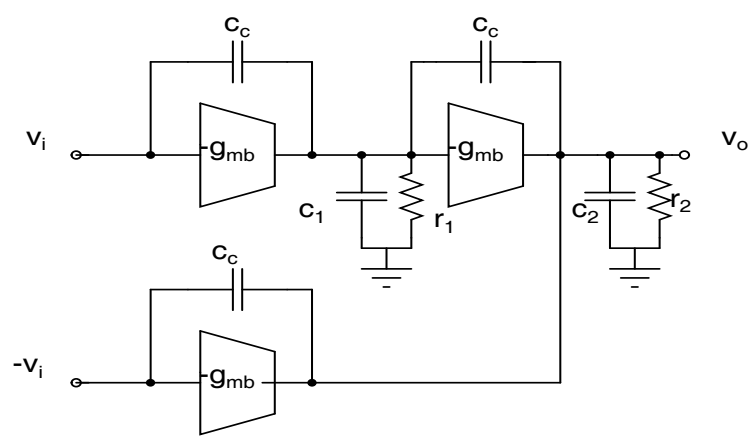

Fig. 6. Small signal model of feed-forward OTA

\section{Simulation Results}

A bulk driven differential transconductor is designed in $180 \mathrm{~nm}$ technology to operate at $0.5 \mathrm{~V}$ supply. The input and output common mode voltages of the transconductor are fixed at $0.25 \mathrm{~V}$. In Fig. 5, gates of $\mathrm{M}_{1}$ and $\mathrm{M}_{2}$ are biased to carry a quiescent current of $10 \mu \mathrm{A}$ and are sized for a bulk transconductance of $45 \mu \mathrm{S}$. Gates of $\mathrm{M}_{3}$ and $\mathrm{M}_{4}$ are biased 
with a common mode feedback voltage which sets the output common mode voltage. Transconductor is modeled and modeled values are as follows.

$$
\begin{aligned}
& \mathrm{R}_{\text {in }}=14.36 \mathrm{M} \Omega \\
& \mathrm{R}_{\text {out }}=385.8 \mathrm{k} \Omega \\
& \mathrm{C}_{\text {in }}=443.577 \mathrm{fF} \\
& \mathrm{C}_{\text {out }}= 189.632 \mathrm{fF} \\
& \quad \mathrm{C}_{\mathrm{c}}=0.68248 \mathrm{fF}
\end{aligned}
$$

After compensation. It is worth noting that, without the compensation, $\mathrm{C}_{\mathrm{c}}$ was $47 \mathrm{fF}$. Fig. 7 compares the frequency response of the transistor level transconductor and that of its model.

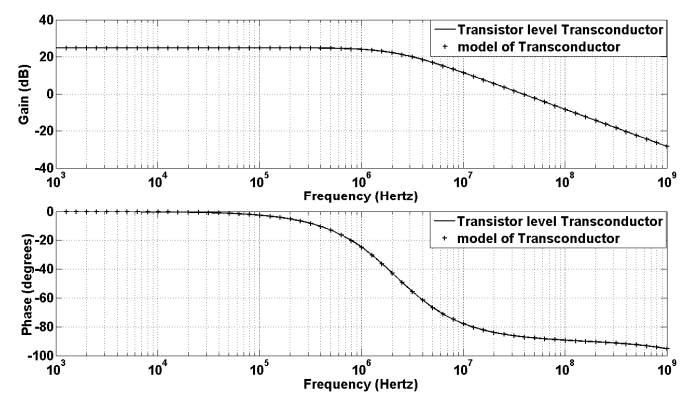

Fig. 7. Frequency response of Transistor level differential Transconductor and of its model

A bulk driven feed-forward compensated OTA then built using the transconductors. Fig. 8 compares the frequency response of the transistor level differential OTA and of its model (Fig. 4). OTA has an open loop DC gain of $44 \mathrm{~dB}$. Under no load condition the OTA has a $3 \mathrm{~dB}$ bandwidth of $601 \mathrm{kHz}, \mathrm{UGB}$ of $22 \mathrm{MHz}$, phase margin of $68.5^{\circ}$ and a gain margin of $54.89 \mathrm{~dB}$. It is to be noted that, if it were a Miller compensation, for the same UGB of $22 \mathrm{MHz}$, the 3-dB bandwidth would have been $138 \mathrm{kHz}$. For a pure capacitive load of $1 \mathrm{pF}$, OTA has $3 \mathrm{~dB}$ bandwidth of $408 \mathrm{kHz}$, UGB of $9.07 \mathrm{MHz}$, a phase margin of $45^{\circ}$ and a gain margin of $66 \mathrm{~dB}$. If resistive loads are considered, the phase margin is sure to

\begin{tabular}{|c|c|c|}
\hline \multicolumn{2}{|c|}{ Parameter } & $\begin{array}{l}\text { Simulate } \\
\mathrm{d} \text { values } \\
\text { of OTA }\end{array}$ \\
\hline \multicolumn{2}{|l|}{ Supply [V] } & 0.5 \\
\hline \multicolumn{2}{|l|}{ Open loop DC gain [dB] } & 44 \\
\hline \multirow[b]{2}{*}{$3 \mathrm{~dB}$ bandwidth $[\mathrm{kHz}]$} & No load & 601 \\
\hline & I pF capacitive load & 408 \\
\hline \multirow[b]{2}{*}{ UGB [MHz] } & No load & 22 \\
\hline & I pF capacitive load & 9.07 \\
\hline \multirow[b]{2}{*}{$\begin{array}{l}\text { Phase margin } \\
\text { [degree] }\end{array}$} & No load & 68.5 \\
\hline & I pF capacitive load & 45 \\
\hline \multirow[b]{2}{*}{ Gain margin $[\mathrm{dB}]$} & No load & 54.89 \\
\hline & I pF capacitive load & 66 \\
\hline \multicolumn{2}{|l|}{ Power $[\mu \mathrm{W}]$} & $30 *$ \\
\hline \multicolumn{2}{|l|}{ Technology $[\mu \mathrm{m}]$} & 0.18 \\
\hline \multirow{2}{*}{$\begin{array}{l}\text { Input referred } \\
\text { noise }[\mathrm{nV} / \sqrt{\mathrm{Hz}}]\end{array}$} & @ $10 \mathrm{kHz}$ & 95.8 \\
\hline & (a) $1 \mathrm{MHz}$ & 65.72 \\
\hline
\end{tabular}
be improved as the damping increases. Table I lists the parameters of the OTA. A comparison of performance parameters of the designed OTA with other low voltage OTAs found in the literature is listed in Table II.

\begin{tabular}{|c|c|c|c|c|c|c|c|}
\hline Parameter & {$[4]$} & [8] & [9] & [10] & [11] & [12] & $\begin{array}{l}\text { Present } \\
\text { work }\end{array}$ \\
\hline Supply (V) & 0.5 & 1 & 1 & 0.8 & 0.9 & 1.3 & 0.5 \\
\hline $\begin{array}{l}\text { DC gain } \\
(\mathrm{dB})\end{array}$ & 52 & 70 & 49 & 53 & 70 & 84 & 44 \\
\hline $\begin{array}{l}\text { UGB } \\
(\mathrm{MHz})\end{array}$ & 2.5 & 0.2 & 1.3 & 1.3 & $\begin{array}{l}0.00 \\
6 \\
\end{array}$ & 1.3 & 9.07 \\
\hline Power $(\mu \mathrm{W})$ & 110 & 5 & 300 & -- & 0.5 & 460 & $30 *$ \\
\hline $\begin{array}{l}\text { Technology } \\
(\mu \mathrm{m})\end{array}$ & 0.18 & 0.35 & 2 & 0.5 & 2.5 & 0.7 & 0.18 \\
\hline $\mathrm{C}_{\mathrm{L}}(\mathrm{pF})$ & 20 & 7 & 22 & 20 & 12 & -- & 1 \\
\hline $\begin{array}{l}\text { Input } \\
\text { referred } \\
\text { noise@10 } \\
\mathrm{kHz} \\
{[\mathrm{nV} / \sqrt{\mathrm{Hz}}]}\end{array}$ & 220 & 260 & 181 & -- & -- & -- & 95.8 \\
\hline $\begin{array}{l}\text { Input } \\
\text { referred } \\
\text { noise @ } 1 \\
\mathrm{MHz} \\
{[\mathrm{nV} / \sqrt{\mathrm{Hz}}]}\end{array}$ & 90 & -- & 43.6 & -- & -- & -- & 65.72 \\
\hline
\end{tabular}

* excluding CMFB circuit

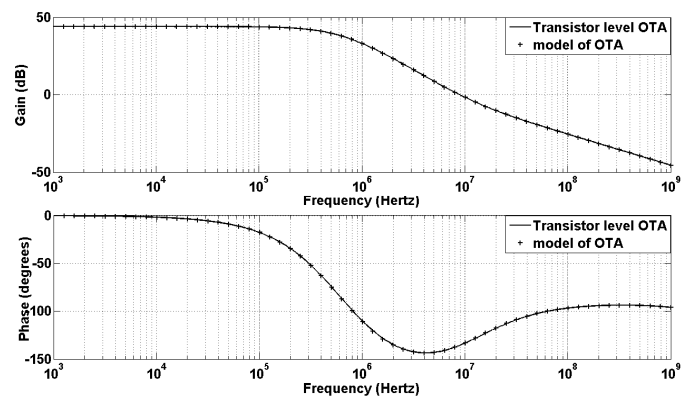

Fig. 8. Frequency response of feed-forward OTA

TABLE II: COMPARISON WITH OTHER LOW VOLTAGE OTA DESIGNS

* excluding CMFB circuit

To demonstrate the application of the designed OTA, a fifth order Chebyshev low pass filter is designed and the schematic of the filter is shown in Fig. 9. The filter has a bandwidth of $480 \mathrm{kHz}$ and a pass band ripple of $1 \mathrm{~dB}$. It is derived from the ladder architecture [6].

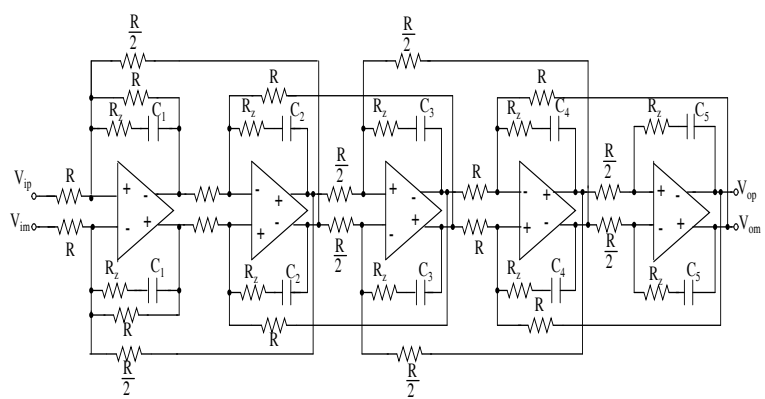

Fig. 9. Schematic of fifth order chebyshev filter.

Fig. 10 shows the magnitude response of the transistor level filter. It can be seen that the response closely matches with the ideal response up to $1 \mathrm{MHz}$ where the attenuation of the filter is about $50 \mathrm{~dB}$. The deviation beyond $1 \mathrm{MHz}$ is attributed to parasitic poles/zeros.

\section{CONCLUSIONS}

A fully differential low power OTA is described. The OTA designed is in $180 \mathrm{~nm}$ CMOS technology and is feed-forward compensated. It has $44 \mathrm{~dB} \mathrm{DC}$ gain, 9.07 $\mathrm{MHz} \mathrm{UGB}, 45^{\circ}$ phase margin and $66 \mathrm{~dB}$ gain margin at $1 \mathrm{pF}$ pure capacitive 
load consuming a power of $30 \mu \mathrm{W}$ from $0.5 \mathrm{~V}$ supply. A fifth order Chebyshev low pass active - RC filter with the cutoff frequency of $480 \mathrm{kHz}$ is designed as an application of the OTA. Filter response closely matches with the ideal response up to $1 \mathrm{MHz}$ where the attenuation of the filter is $50 \mathrm{~dB}$.

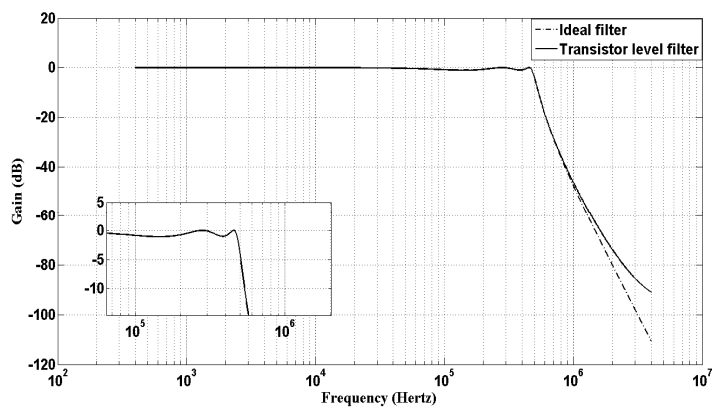

Fig. 10. Magnitude response of fifth order chebyshev filter

\section{REFERENCES}

[1] C. F. Wheatley and H. A. Wittlinge, "OTA obsoletes OPAMP," in Proc. of National Econ. Conference I, pp.152-157, 1969.

[2] Y. P. Tsividis, "Integrated Continuous time filters design - An Overview," IEEE Journal of solid state circuits, vol. 29, no. 3, pp. 166-176, March 1994.

[3] A .Guzinski, M. Bialko, and J. C. Matheau, "Body driven differential amplifier for applications in continuous time active-C filter," in Proc. European Conf. Circuit Theory and Design (ECCTD'87), pp. 315-320, 1987.

[4] S. Chatterjee, Y. Tsividis, and P. Kinget, "0.5V Analog Circuit Techniques and their Application in OTA and filter design," IEEE Journal of Solid-state Circuits, vol. 40, no. 12, pp. 2373-2387, 2005.

[5] J. N. Harrison and N. Weste, " $350 \mathrm{MHz}$ Opamp-RC filter in $0.18 \mu \mathrm{m}$ CMOS," IEE Electronics Letters, pp.259-260, 2002.

[6] T. Laxminidhi, V. Prasadu and S. Pavan, "Widely programmable high frequency active RC filters in CMOS technology," IEEE transactions on circuits \& Systems, vol.56, no. 2, pp.327-336, February 2009.

[7] B. Thandri and J. S. Martinez, "A Robust feedforward compensation scheme for multistage operational Transconductance Amplifiers with no miller capacitors," IEEE J. Solid State Circuits, vol. 38, no.2, pp. 237- 243, Feb. 2003

[8] K. Lasanen, E. R. Ruotsalainen, and J. Kostamovaara, "A 1- V 5 $5 \mathrm{~W}$ CMOS-Opamp with Bulk-Driven Input Transistors," in Proc. 43rd IEEE Midwest Symp. on Circuits and Systems, pp. 1038-1041, pp. 8-11, 2000

[9] B. Blalock, P. Allen, and G.Rincon-Mora, "Designing 1-V op-amps using standard digital CMOS technology," IEEE Trans. Circuits Systems II, Analog Digital Signal Process, vol. 45, no. 7, pp. 769-780, 1998.

[10] T. Lehmann and M. Cassia, "1-V power supply CMOS cascode amplifier", IEEE J. Solid State Circuits, vol. 36, no. 7, pp. 1082-1086, July 2001.

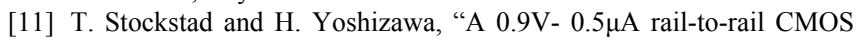
operational amplifier," IEEE J. Solid State Circuits, vol. 37, pp. 286-292, 2002.

[12] G. Ferri and W. Sansen, "A 1.3V opamp in standard $0.7 \mu \mathrm{m}$ CMOS with constant $\mathrm{g}_{\mathrm{m}}$ and rail-to-rail input and output stages," IEEE Int. Solid State Circuits Conf. Dig. Tech. Papers, vol. 478, 1996, pp. 382-383.

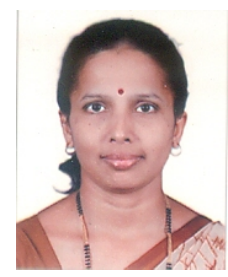

Rekha S. was born in Puttur, India. She received the B.E. degree in Instrumentation Technology from SJCE Mysore, India and M.Tech. in Industrial Electronics from NITK (KREC) Surathkal, India.Since 2007 she has been an Assistant Professor with the National Institute of Technology Karnataka, Surathkal, India. Her research interests include analog and digital VLSI design.

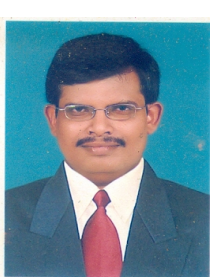

Tonse Laxminidhi was born in Udupi, South India, in 1975. He received the B.Tech degree in Electrical and Electronics Engineering from NMAM Institute of Technology, Nitte, India, in 1996. In 1998 he received the M.Tech degree in Industrial Electronics from the National Institute of Technologyi-Karnataka (NITK), Surathkal, India. He obtained his $\mathrm{Ph} . \mathrm{D}$. degree from the Departement of Electrical Engineering, Indian Institute of Technology, Madras. His research interests include analog and mixed mode integrated circuits and power management circuits. He is a faculty in the Department of Electronics and Communication Engineering, NITK Surathkal since 1998 and currently holding the position of Associate Professor. 